\title{
Correction to: A robust two-stage active disturbance rejection control for the stabilization of a riderless bicycle
}

\author{
Mauro Baquero-Suárez ${ }^{1,2}$ • John Cortés-Romero ${ }^{1}$. \\ Jaime Arcos-Legarda ${ }^{1}$ Horacio Coral-Enriquez ${ }^{1,2}$
}

Published online: 19 March 2019

(c) Springer Nature B.V. 2019

\section{Correction to: Multibody Syst Dyn (2019) 45:7-35 https://doi.org/10.1007/s11044-018-9614-y}

In the original publication the affiliation of author John Cortés-Romero was given in its translated form (National University of Colombia). It is a legal requirement of this university that its name be given in the original Spanish in publications (Universidad Nacional de Colombia) and this correction article is published to amend this.

Publisher's Note Springer Nature remains neutral with regard to jurisdictional claims in published maps and institutional affiliations.

The online version of the original article can be found under https://doi.org/10.1007/s11044-018-9614-y.

J. Cortés-Romero jacortesr@unal.edu.co

1 Universidad Nacional de Colombia, Sede Bogotá, Facultad de Ingeniería, Departamento de Ingeniería Eléctrica y Electrónica, Av. K30 No. 45-03, Edif. 411 Of. 222, Bogotá D.C., Colombia

2 Engineering Faculty, University of San Buenaventura, Av. K8H No. 172-20, Edif. Diego Barroso Of. 204, Bogotá D.C., Colombia 